\title{
Mast cells modulate the pathogenesis of elastase-induced abdominal aortic aneurysms in mice
}

\author{
Jiusong Sun, ${ }^{1}$ Galina K. Sukhova, ${ }^{1}$ Min Yang, ${ }^{1,2}$ Paul J. Wolters, ${ }^{3}$ Lindsey A. MacFarlane, ${ }^{1}$ \\ Peter Libby, ${ }^{1}$ Chongxiu Sun, ${ }^{1}$ Yadong Zhang, ${ }^{1}$ Jian Liu, ${ }^{1}$ Terri L. Ennis, ${ }^{4}$ Rebecca Knispel, ${ }^{5}$ \\ Wanfen Xiong, ${ }^{5}$ Robert W. Thompson, ${ }^{4}$ B. Timothy Baxter, ${ }^{5}$ and Guo-Ping Shi ${ }^{1}$

\begin{abstract}
'Department of Medicine, Brigham and Women's Hospital and Harvard Medical School, Boston, Massachusetts, USA. 2Department of Rheumatology, Nanfang Hospital and Nanfang Medical University, Guangzhou, People's Republic of China. ${ }^{3}$ Department of Medicine, UCSF School of Medicine, San Francisco, California, USA. ${ }^{4}$ Department of Surgery, Washington University School of Medicine, St. Louis, Missouri, USA. ${ }^{5}$ Department of Surgery, University of Nebraska Medical Center, Omaha, Nebraska, USA.
\end{abstract}

\begin{abstract}
Abdominal aortic aneurysm (AAA), an inflammatory disease, involves leukocyte recruitment, immune responses, inflammatory cytokine production, vascular remodeling, neovascularization, and vascular cell apoptosis, all of which contribute to aortic dilatation. This study demonstrates that mast cells, key participants in human allergic immunity, participate in AAA pathogenesis in mice. Mast cells were found to accumulate in murine AAA lesions. Mast cell-deficient $\mathrm{Kit}^{W-s h} / \mathrm{Kit}^{W-s h}$ mice failed to develop AAA elicited by elastase perfusion or periaortic chemical injury. $\mathrm{Kit}^{W-s h} / \mathrm{Kit}^{W-s h}$ mice had reduced aortic expansion and internal elastic lamina degradation; decreased numbers of macrophages, $\mathrm{CD3}^{+} \mathrm{T}$ lymphocytes, SMCs, apoptotic cells, and CD31+ microvessels; and decreased levels of aortic tissue IL-6 and IFN- $\gamma$. Activation of mast cells in WT mice via C48/80 injection resulted in enhanced AAA growth while mast cell stabilization with disodium cromoglycate diminished AAA formation. Mechanistic studies demonstrated that mast cells participated in angiogenesis, aortic SMC apoptosis, and matrix-degrading protease expression. Reconstitution of $\mathrm{Kit}^{\mathbb{W - s h}} / \mathrm{Kit}^{\mathbb{W - s h}}$ mice with bone marrow-derived mast cells from WT or TNF- $\alpha^{-/-}$mice, but not from IL-6 $6^{-/-}$or IFN- $\gamma^{-/-}$mice, caused susceptibility to AAA formation to be regained. These results demonstrate that mast cells participate in AAA pathogenesis in mice by releasing proinflammatory cytokines IL-6 and IFN- $\gamma$, which may induce aortic SMC apoptosis, matrix-degrading protease expression, and vascular wall remodeling, important hallmarks of arterial aneurysms.
\end{abstract}

\section{Introduction}

Abdominal aortic aneurysm (AAA), a common aortic disease in the elderly, with an unknown pathogenesis, is characterized by extensive tissue remodeling, neovascularization, inflammatory cell infiltration, and vascular cell apoptosis, all of which contribute to aortic dilatation, the sine qua non of the disease (1). Leukocyte recruitment is a key feature of human AAA. After infiltration, the neutrophils, macrophages, and lymphocytes in human AAA lesions produce a spectrum of proinflammatory cytokines and matrix-degrading proteases that promote formation of AAA (1). Selective depletion of neutrophils (2), lymphocytes (3), matrixdegrading proteases $(4,5)$, or proinflammatory cytokines (6) impairs experimental AAA formation.

Mast cells are another inflammatory cell type recently identified in human aortic lesions, including those of atherosclerosis and AAA $(7,8)$. Classically, mast cells have been described as essential effector cells of immediate hypersensitivity and chronic allergic reactions that contribute to asthma, atopic dermatitis, and other allergic diseases (9). Despite the lack of direct evidence of mast cell participation in either atherosclerosis or AAA, enhanced accumulation of mast cells during human atherogenesis and AAA formation suggests that mast

Nonstandard abbreviations used: AAA, abdominal aortic aneurysm; BMMC, bone marrow-derived mast cell; DSCG, disodium cromoglycate; IEL, internal elastic lamina; MCP-1, monocyte chemoattractant protein-1; PDTC, pyrrolidine dithiocarbamate. Conflict of interest: The authors have declared that no conflict of interest exists. Citation for this article: J. Clin. Invest. 117:3359-3368 (2007). doi:10.1172/JCI31311. cells play a role in the pathogenesis of these vascular diseases. For example, active chymase, a unique mast cell protease important in the formation of angiotensin II and activation of $\operatorname{MMP}(10,11)$, has been found at increased levels in extracts of human AAA lesions. Chymase-positive mast cells were detected in the media and adventitia in human AAA (8). Pharmacological inhibition of chymase activity reduces AAA progression in hamsters (12). In addition to a unique set of proteases, mast cells also release proinflammatory cytokines (IFN- $\gamma$, TNF- $\alpha$, and IL-4, -5, -6, and -13) and chemokines (monocyte chemoattractant protein-1 [MCP-1], IL-8, RANTES), all of which may directly or indirectly participate in AAA formation. Stabilization of mast cells with disodium cromoglycate (DSCG) blocked the increase of plasma IL-6 in ApoE $E^{-/-}$mice (13). Many in vitro and in vivo studies have also demonstrated that IL-6 plays a role in lymphocyte activation and that IFN- $\gamma$ stimulates lymphocytes, macrophages, ECs, and fibroblasts. In addition to activating T cells and B cells, IL-6 is required for fibroblast and EC MCP-1 expression, macrophage and leukocyte recruitment, MMP expression, angiogenesis, angiotensin II-mediated macrophage oxidized LDL uptake, and angiotensin II-mediated reactive oxygen species production and endothelial dysfunction, all of which are important to AAA pathogenesis (7). Mice lacking IFN- $\gamma$ are resistant to AAA (3). Injection of IFN- $\gamma$ into $\mathrm{CD}^{+}$ $T$ cell-depleted mice, which are resistant to aneurysm induction, can partially reconstitute aneurysms in $\mathrm{CD}^{-/-}$mice (3).

However, other inflammatory cell types in AAA lesions, such as macrophages, neutrophils, and lymphocytes, also produce potent extracellular matrix proteases as well as the aforementioned mast 


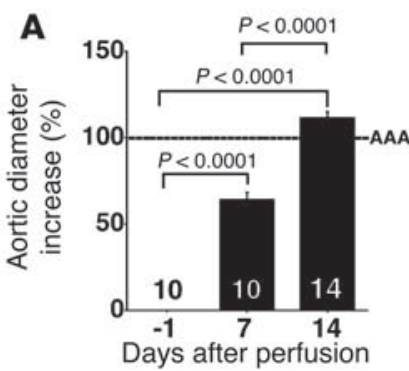

B

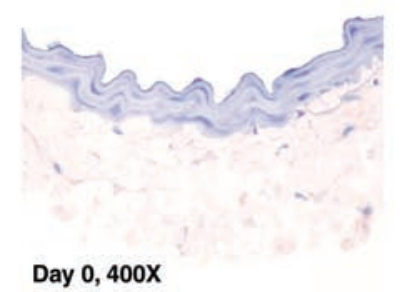

C

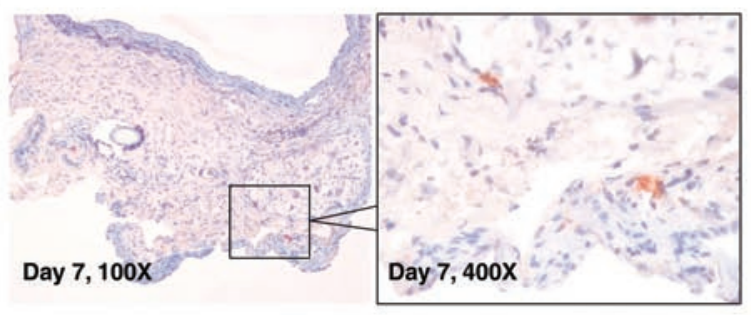

D

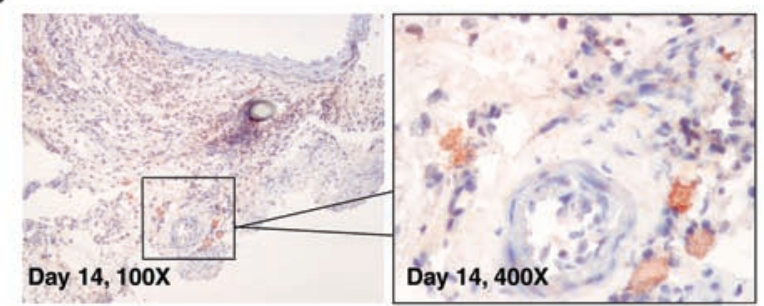

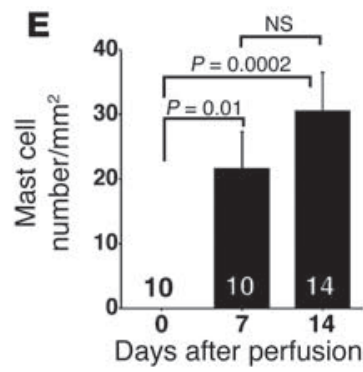

Days after perfusion

Figure 1

Mast cell accumulation in elastase perfusion-induced AAA. (A) Percentage of aortic diameter increase of AAA lesions harvested from different time points. (B-D) Immunostaining with mMCP-4 polyclonal antibody revealed accumulation of mast cells in the adventitia 7 (C) and 14 (D) days after perfusion but hardly any mast cells in aortas harvested immediately after perfusion (day 0, B). (E) Mast cell content in AAA lesions harvested from different time points. Data are presented as mean $\pm \mathrm{SE}$, and $P<0.05$ was considered significant (Mann-Whitney test). Number of animals for each experiment is indicated in the bars.

cell mediators. For example, macrophages are a major source of the vascular wall destructive cysteine proteases $(14), \operatorname{MMP}(4,5)$, and the proinflammatory cytokines TNF- $\alpha$, IL- $1 \beta$, and IFN- $\gamma(3$, $15)$, implicated in the development of human and murine AAA. Lymphocytes produce Th1 and Th2 cytokines in human arterial diseases $(3,15)$. Our recent studies demonstrated that $\mathrm{CD}^{+} \mathrm{T}$ cells, the major lymphocytes in human AAA lesions (3), produce MMP-9 and the cysteine proteases cathepsins S, K, and L (16), all of which are essential to vasculature remodeling $(4,14)$.

In this study, we used an aorta elastase perfusion-initiated mouse AAA model to determine whether mast cells modulate AAA formation. Reconstitution of mast cells from different cytokinedeficient mice into mast cell-deficient mice identified mast cell mediators essential to AAA. Finally, we determined whether we can regulate mouse AAA formation by activating or stabilizing mast cell activities in vivo.

\section{Results}

Mast cell accumulation and AAA formation. Biochemical observations revealed high numbers of chymase- and tryptase-positive mast cells in human AAA lesions and suggested an association of mast cell accumulation and AAA progression (8). To test this hypothesis, we used an established elastase perfusion model to produce AAA in mice $(2,4)$. In this model, the infrarenal aorta is locally exposed to pancreatic elastase, and aortic expansion forms over a period of 2 weeks as defined by an increase of aortic diameter by $100 \%$ greater than that before perfusion (4). Consistently, all mice developed AAA 14 days after elastase perfusion (Figure 1A). While normal aortas contained few if any mast cells (Figure 1, B and E), a significant increase of mast cell content appeared in the adventitia 7 days after perfusion (Figure 1, C and E) with further increase at 14 days after perfusion (Figure 1, D and E). Murine mast cells appear predominantly in the adventitia (Figure 1, C and D). These obser- vations indicate that mast cells populate AAA induced by elastase perfusion and provide an opportunity to determine experimentally whether AAA formation requires mast cells.

Reduced AAA in mast cell-deficient mice. Accumulation of mast cells in AAA lesions suggests a participation of these cells in this disease. To test this hypothesis, we studied mast cell-deficient $K i t^{W-s h} / K_{i t}{ }^{W-s h}$ mice in the elastase perfusion-induced AAA model. Kit ${ }^{W-s h} / K_{i t}{ }^{W-s h}$ mice contain a de novo inversion mutation consisting of a break point at the upstream regulatory region of the $c$-kit receptor gene that results in reduced Kit receptor expression and defective mast cell maturation and survival (17). However, this mutation does not affect the number or function of blood leukocytes, including lymphocytes (18). Elastase activities of bone marrow-derived neutrophils $\left(6,185 \pm 94\right.$ versus $\left.6,195 \pm 26, \mathrm{OD}_{515 \mathrm{~nm}} ; P=0.92\right)$ and blood monocytes $\left(5,980 \pm 167\right.$ versus $\left.6,274 \pm 62, \mathrm{OD}_{515 \mathrm{~nm}} ; P=0.18\right)$ showed no significant difference between WT mice and $\mathrm{Kit}^{\mathrm{W}-\mathrm{s} h}$ / $K i t^{W-s h}$ mice. At baseline, histological analysis did not reveal any aortic wall elastin degradation, loss of medial SMCs, medial SMC apoptosis, or infiltration of macrophages and $\mathrm{T}$ cells in aortas from either WT or $\mathrm{Kit}^{\mathrm{W}-\mathrm{sh}} / \mathrm{Kit}^{\mathrm{W}-\mathrm{sh}}$ mice before the elastase perfusion (data not shown). However, $K i t^{W-s h} / K^{W} t^{W-s h}$ mice were protected from AAA formation during 56 days following elastase perfusion. After perfusion expansion (day 0), the abdominal aortas of $\mathrm{Kit}^{W-s h} / \mathrm{Kit}^{\mathrm{W}-\mathrm{sh}}$ mice showed no further expansion on days 7, 14, and 56, whereas all WT control mice had an average of more than $110 \%$ and approximately $170 \%$ aortic expansion 14 and 56 days after perfusion, respectively (Figure 2A). Importantly, while the lumen diameters of both WT and $K i t^{W-s h} / K_{i t}^{W-s h}$ mice increased at day 0 by nearly $30 \%$ due to elastase perfusion, the lumen diameters of $\mathrm{Kit}^{\mathrm{W}-\mathrm{sh}} / \mathrm{Kit}^{\mathrm{W}-\mathrm{sh}}$ mice decreased continuously to those of preperfusion at day 56 after perfusion. In contrast, although there was a decrease on day 7, lumen diameters of WT mice increased consistently over time and reached $30 \%$ at day 56 after perfusion (Figure 2B). 

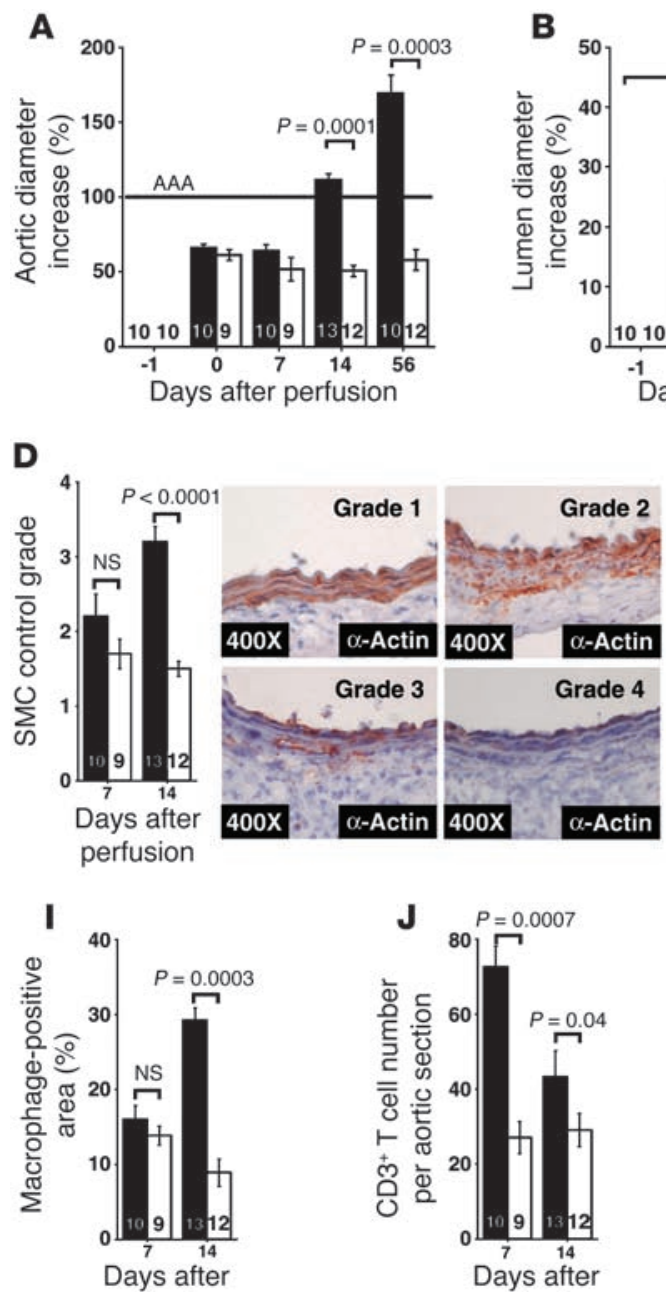

perfusion

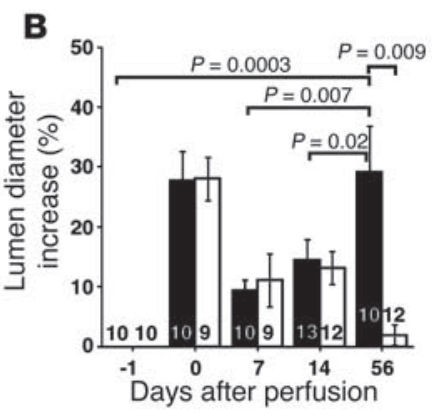

E
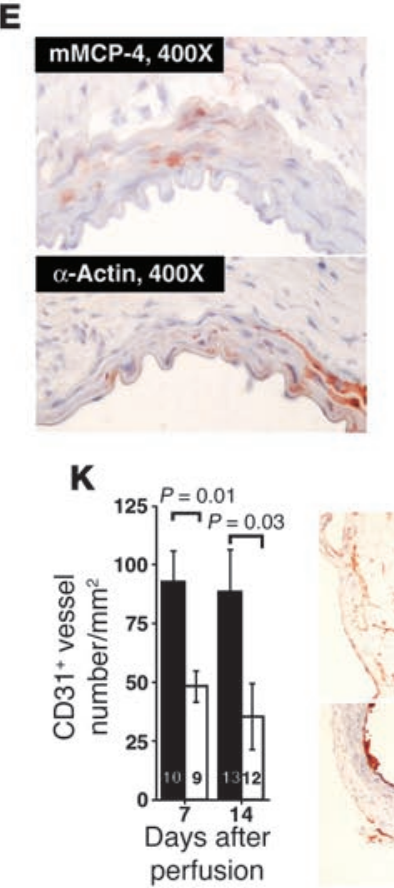
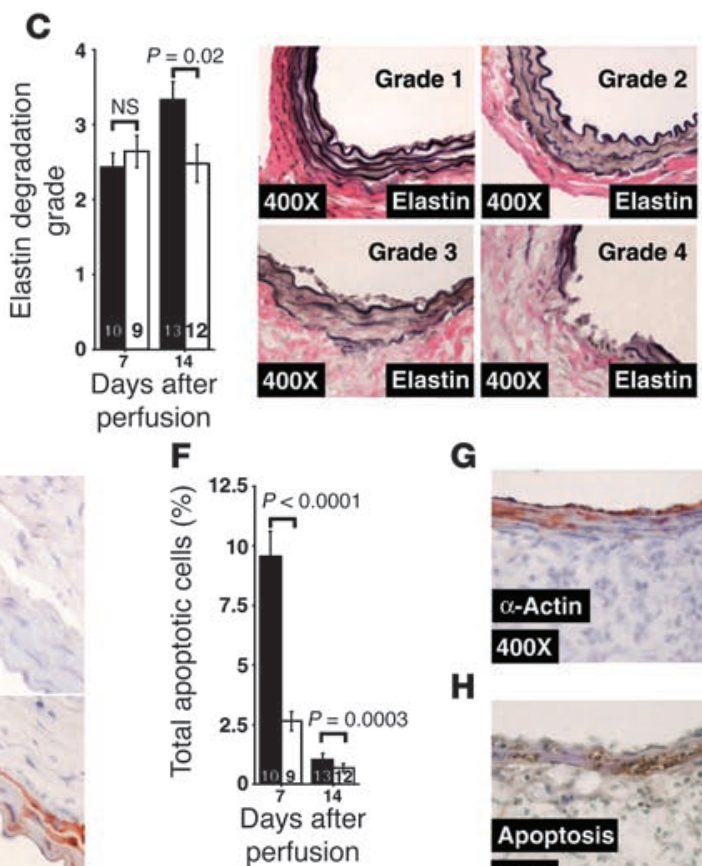

G

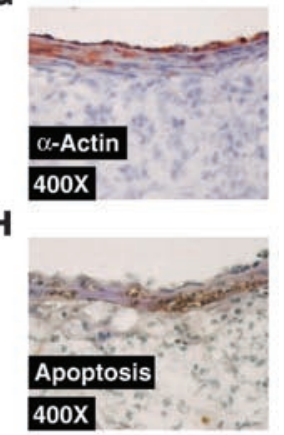

L
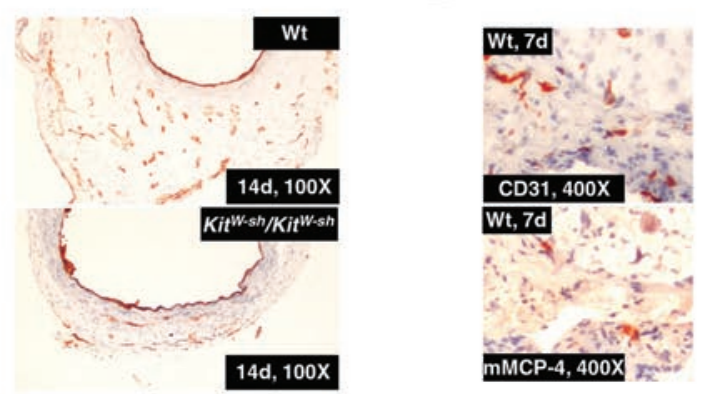

Figure 2

Characterization of AAA lesions in both WT (black bars) and Kit ${ }^{W-s h} / K_{i t}{ }^{W-s h}$ mice (white bars). (A) Aortic diameter-increase percentages in WT and $K i t^{W-s h} / K i t^{W-s h}$ mice. (B) Lumen diameter-increase percentages in Kit ${ }^{W-s h} / K_{i t}{ }^{W-s h}$ and WT mice. (C) Medial elastin degradation in WT and Kit ${ }^{W-s h} / K_{i t}{ }^{W-s h}$ mice. Elastin degradation-grading (4 grades) keys are indicated in right panels. (D) Lesion SMC contents in WT and Kit ${ }^{W-s h} / K_{i t}{ }^{W-s h}$ mice. SMC content-grading keys (4 grades) are shown in right panels. (E) Serial sections from the same aortic tissue block from a WT mouse (14-day time point) were stained for mMCP-4 and $\alpha$-actin to show the presence of mast cells and loss of SMCs in the media. (F) Absence of mast cells reduced total lesion cell apoptosis at both time points. (G) AAA lesion was stained with $\alpha$-actin to show a loss of medial SMCs. (H) AAA lesion was stained for TUNEL-positive cells at the same region as in G. (I) Significantly reduced macrophage content was detected only at a late (14 days) time point. (J) CD3 ${ }^{+} \mathrm{T}$ cell contents in WT and $\mathrm{Kit} \mathrm{W}_{\text {-sh }} / \mathrm{Kit} \mathrm{W}^{\mathrm{W}-\mathrm{sh}}$ mouse lesions from 7-day and 14-day time points. (K) CD31+ microvessel contents in aortas from Kit ${ }^{W-s h} / K_{i t}{ }^{W-s h}$ and WT mice at both time points. Representative CD31 staining of aortas from the 14-day time point are shown in the right panels. (L) Serial sections were immunostained for CD31 and mMCP-4 to show the presence of mast cells in area with microvessels. Data in all bar graphs are presented as mean $\pm \mathrm{SE}$, and $P<0.05$ was considered significant (Mann-Whitney test). Number of animals for each experiment is indicated in the bars.

Therefore, the AAA protection in $K i t^{W-s h} / K^{W} t^{W-s h}$ mice at day 14 was largely due to attenuation of adventitial thickening, whereas AAA protection in $K i t^{W-s h} / K i t^{W-s h}$ mice at 56 days was the result of a combination of attenuation of both luminal expansion and adventitial thickening. Histological analysis of $\mathrm{Kit}^{\mathrm{W}-\mathrm{sh}} / \mathrm{Kit}^{\mathrm{W}-\mathrm{sh}}$ mice showed better preservation of the internal elastic laminae (IELs) (Figure 2C), consistent with higher medial SMC content on day 14 , as determined by semiquantitative grading (Figure 2D). Therefore, reduced levels of medial SMCs in WT mice may result from enhanced IEL fragmentation and an increase in medial SMC death. Although most mast cells reside in the adventitia, clusters of mast cells exist in the media where elastin degradation and SMC apoptosis occur. Immunostaining of serial sections with mouse MCP-4 (mMCP-4) (mast cells) (19) and $\alpha$-actin (SMCs) demonstrated numerous mast cells but fewer SMCs in the media (Figure 2E), suggesting a role of mast cells in medial SMC apoptosis. Further, activated mast cells in the adventitia may also release granular contents capable of acting on cells at a distance, such as those in the media. Compared with $K i t^{W-s h} / K i t^{W-s h}$ mice, WT mice showed overall more apoptotic cells on days 7 and 14 ( 4-fold) (Figure 2F). By staining adjacent sections for both SMCs ( $\alpha$-actin) (Figure $2 \mathrm{G}$ ) and apoptosis (TUNEL) (Figure 2H), we explored the contribution 


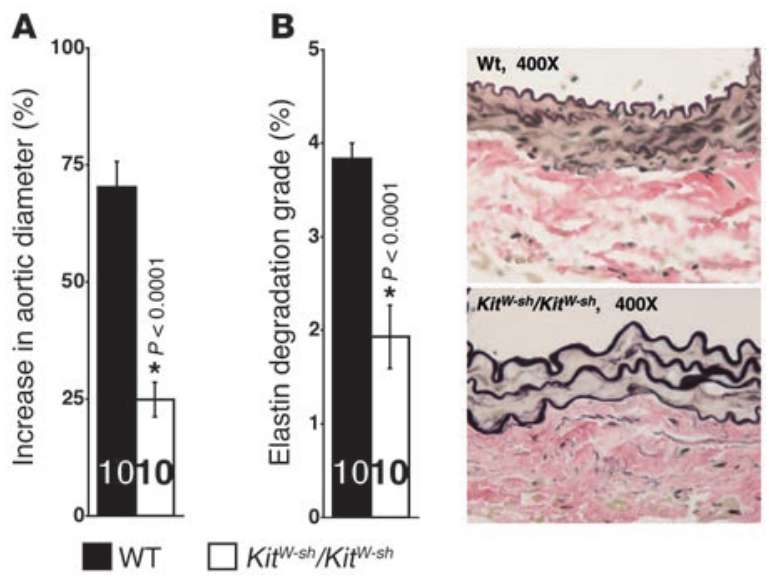

of cell death to the loss of medial SMCs. Media poor in $\alpha$-actin had abundant TUNEL staining. Significantly reduced levels of macrophages (Figure 2I) and $\mathrm{CD}^{+} \mathrm{T}$ cells (Figure 2J) in elastase-perfused $\mathrm{Kit}^{W-s h} / \mathrm{Kit}^{W-s h}$ mice confirmed decreased inflammation.

Neovascularization plays an essential role in AAA formation, and its presence associates with AAA lesion rupture (20). To determine whether mast cells modulate neovascularization, we stained tissue sections with an anti-CD31 antibody and found a reduced content of adventitial CD $31^{+}$microvessels in $\mathrm{Kit}^{W-s h} / \mathrm{Kit}^{W-\text {-sh }}$ mice both 7 and

\section{Figure 3}

Periaortic $\mathrm{CaCl}_{2}$-induced AAA. (A) WT mice showed much higher aortic expansion than $\mathrm{Kit}^{\mathrm{W} \text {-sh }} / \mathrm{Kit}{ }^{\mathrm{W}}$-sh mice 6 weeks after periaortic $\mathrm{CaCl}_{2}$ injury. (B) Elastin degradation was also reduced in $\mathrm{Kit}{ }^{\mathrm{W}-\mathrm{sh}} / \mathrm{Kit} \mathrm{W}^{\mathrm{W} h}$ mice. Representative photographs showing elastic laminae degradation are shown in the right panels. Data are presented as mean $\pm \mathrm{SE}$, and $P<0.05$ was considered significant (Mann-Whitney test). Number of animals for each experiment is indicated in the bars. ${ }^{*}$ Compared with WT mice.

14 days after elastase infusion (Figure $2 \mathrm{~K}$ ). Immunostaining of AAA serial sections from WT mice with mMCP-4 and CD31 antibodies demonstrated the presence of both microvessels and mast cells in the adventitia (Figure 2L), indicating a possible interaction between mast cells and ECs.

Observations from the Kit ${ }^{W-s b} / K_{i t} t^{W-s h}$ mice show that mast cells regulate AAA formation and suggest that they do so by modulating directly or indirectly the level of cellular inflammation, angiogenesis, and SMC apoptosis in aortic wall. However, the present data do not exclude the possibility that the reduced inflammation observed resulted from decreased AAA formation rather than the converse.

Mast cells promote periaortic $\mathrm{CaCl}_{2}$-induced $A A A$ formation. To further test the hypothesis of mast cell participation in AAA pathogenesis, we induced AAA formation in WT and $K i t^{W-s h} / K^{2} t^{W-s h}$ mice using a second model of experimental AAA (5). Six weeks after periaortic $\mathrm{CaCl}_{2}$ injury, aortic diameter in WT mice increased more than $70 \%$. In contrast, $K i t^{W-s b} / K_{i t}{ }^{W-s b}$ mice showed a less than $25 \%$ increase in

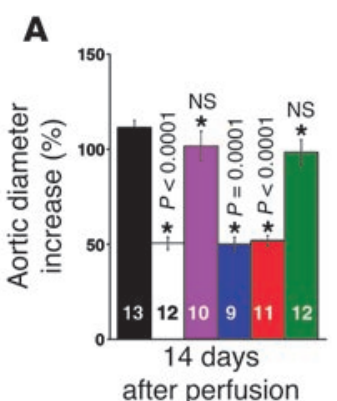

D

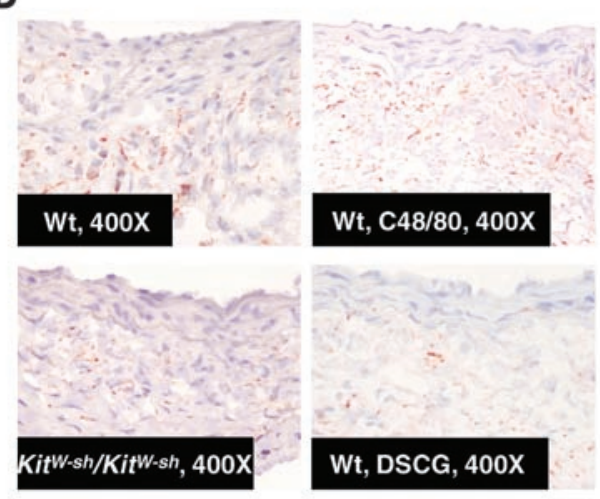

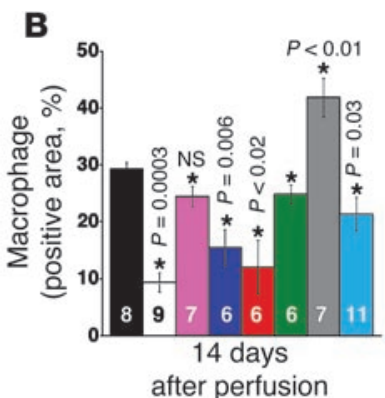

$\mathbf{F}$

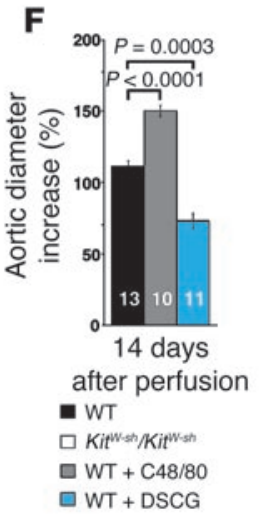

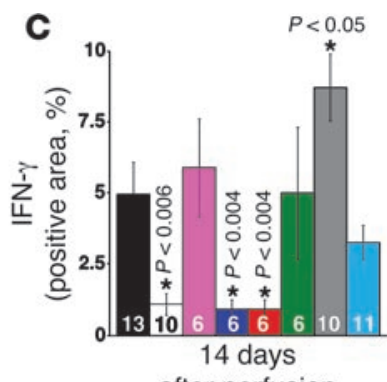

after perfusion

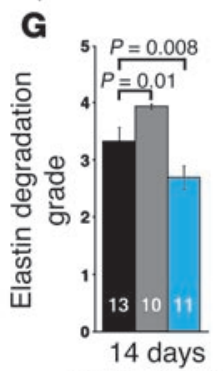

after perfusion

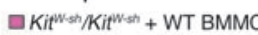

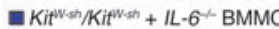

- Kit ${ }^{\text {W-sh }} / \mathrm{Kit}^{\mathrm{W}-\mathrm{sh}}+\mathrm{IFN}-\gamma^{-} \mathrm{BMMC}$

- $K i t^{W \cdot s h} / K_{i t}{ }^{W-s h}+T N F-\alpha^{-j}$ BMMC

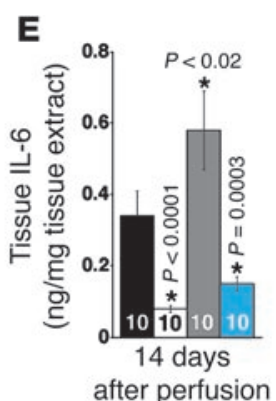

H

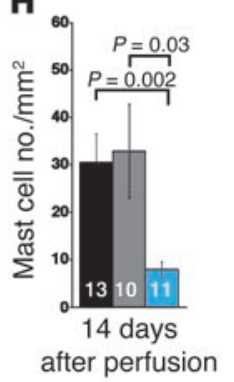

Figure 4

BMMC reconstitution and mast cell activation and stabilization. (A) Aortic expansion in WT, KitW-sh/KitW-sh, and KitW-sh/KitW-sh mice reconstituted with BMMCs from WT, IL-6 $6^{--}$, IFN- $\gamma^{-1}$, and TNF- $\alpha^{-1-}$ mice. (B) Percentage of macrophage-positive areas in AAA lesions from different groups of mice. (C) IFN- $\gamma$ levels in AAA lesions from different groups of mice. (D) IFN- $\gamma$ immunostaining in aortic sections from Kit ${ }^{W-s h} / K_{i t}{ }^{W-s h}$ or WT mice treated with or without C48/80 or DSCG. (E) IL-6 levels in tissue extracts from different groups of mice. (F) Aortic expansion in WT mice treated with or without C48/80 or DSCG. (G) Elastic laminae degradation in WT mice treated with or without C48/80 or DSCG. (H) Mast cell contents in aortas are not affected by C48/80 but decrease in DSCG-treated mice. Different groups of mice are designated with different colored bars as indicated in the legend. All data are from the 14-day time point experiments. Data are presented as mean $\pm \mathrm{SE}$, and $P<0.05$ was considered significant, Mann-Whitney test. Number of animals is indicated in the bars. ${ }^{*}$ Compared with WT mice. 


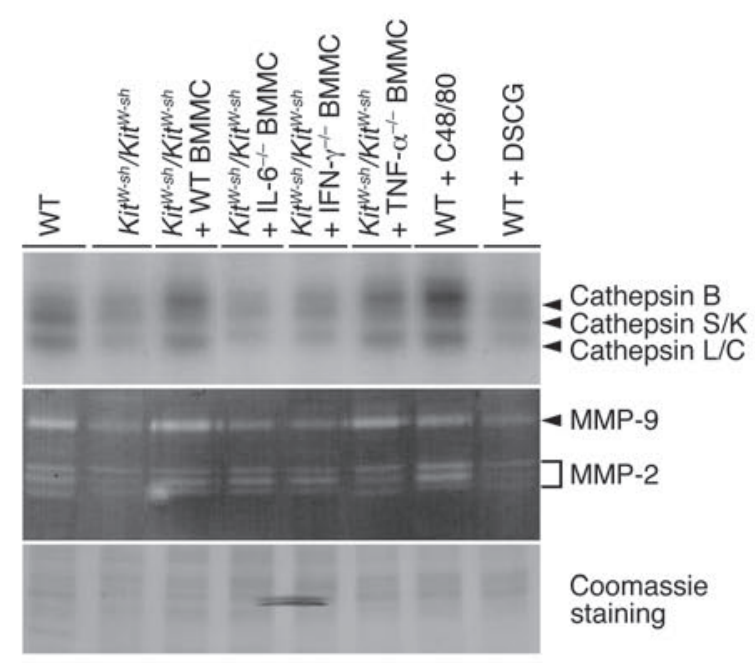

B
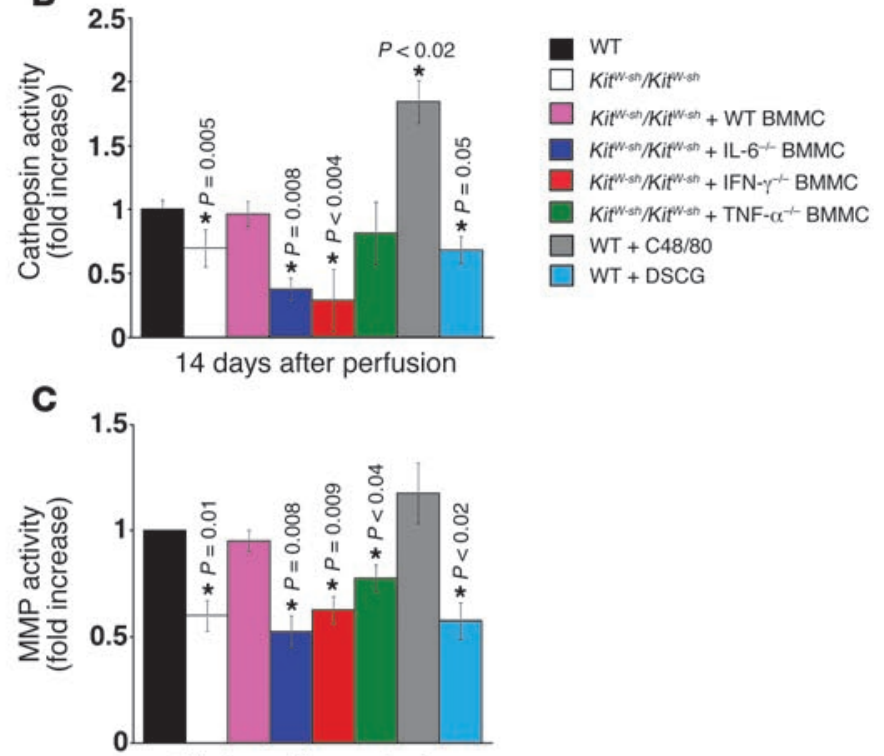

14 days after perfusion

D
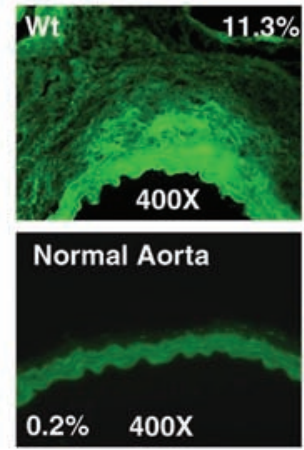

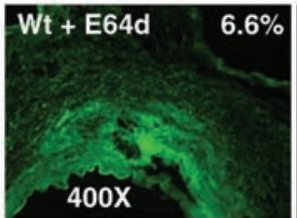

Saline-treated Aorta
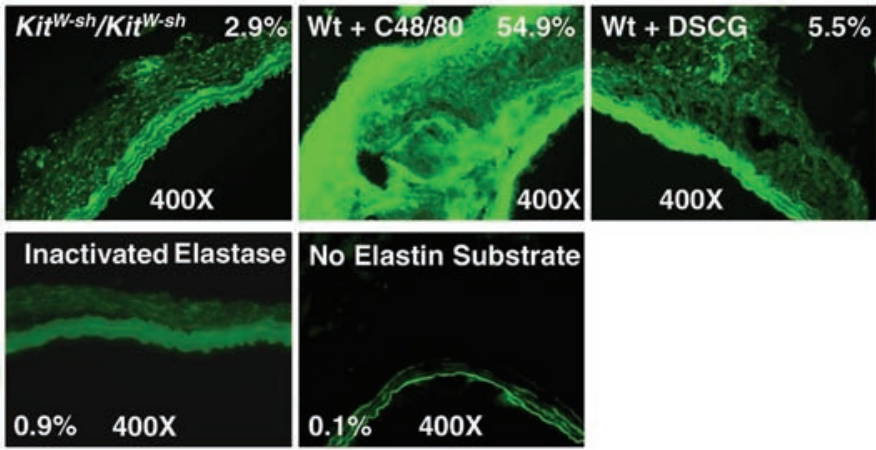

\section{Figure 5}

AAA lesion protease activities. (A) [125I]JPM cysteine protease active site labeling and gelatin gel zymography to detect MMP activities in aortic tissue extracts from different groups of mice. Coomassie staining of SDS-PAGE showed equal protein loading. (B) Densitometric analysis of cathepsin activity changes relative to the density of [ ${ }^{125}$ I]JPM labeling in WT mice. (C) Densitometric analysis of MMP activity changes relative to the density of MMP activity in WT mice. Data are presented as mean \pm SE of 4 independent experiments, and $P<0.05$ was considered significant (Mann-Whitney test). ${ }^{*}$ Compared with WT mice. (D) In situ elastin activity zymography. Normal aorta, saline-treated aorta, heat-inactivated elastase-treated aorta, and active elastase-treated aorta without $D Q$ elastin substrate were used for experimental controls. The first panel (top left) and last panel (bottom right) show parallel sections. The percentage of fluorescence intensity is indicated in each panel. Images were obtained using the same magnification $(\times 400)$ and shutter speed. All data are from the 14-day time point experiments.

aortic diameter (Figure 3A) and preservation of the IEL (Figure 3B). Under these experimental conditions, no lumenal changes were noticed in WT mice 6 weeks after injury and absence of mast cells had no effect on lumen diameters. Our data presented in Figure 3, A and B, indicate that the prevention of AAA formation in $K i t^{W-s h} / K i t^{W-s h}$ mice is independent of the animal models used.

Mast cell IL-6 and IFN- $\gamma$ contribute to AAA formation. In $\mathrm{Kit}^{W-s h} / \mathrm{Kit}^{\mathrm{W}-\mathrm{sh}}$ mice, protection from AAA formation may result either from altered c-kit signaling caused by the inversion mutation of the c-kit receptor gene or the absence of mast cells. To differentiate these possibilities, we introduced bone marrow-derived mast cells (BMMCs) from WT mice and mice deficient in mast cell cytokines IL-6, IFN- $\gamma$, and TNF- $\alpha$ into the tail veins of $\mathrm{Kit}^{\mathrm{W}-\mathrm{sh}} / \mathrm{Kit}^{\mathrm{W}-\mathrm{s} h}$ mice using an established protocol $(18,19,21,22)$, followed by elastase perfusion to induce AAA formation. Reconstitution with WT BMMCs largely restored AAA formation and inflammatory cell (macrophages) infiltration in $\mathrm{Kit}^{W-s h} / \mathrm{Kit}^{W-s h}$ mice 14 days after elastase perfusion (Figure 4, A and B), confirming that the absence of mast cells, rather than altered c-kit signaling, protects $K i t^{W-s h} / K i t^{W-s h}$ mice from AAA formation. Despite TNF- $\alpha$ 's role in mediating some forms of mast cell-associated inflammation (23), $K i t^{W-s h} / K i t^{W-s h}$ mice reconstituted with TNF- $\alpha$-deficient BMMCs developed AAA and enhanced macrophage accumulation similar to those achieved with WT BMMCs. In contrast, BMMCs from IL-6- or IFN- $\gamma$-deficient mice did not have these effects (Figure 4, $\mathrm{A}$ and B). Failed restoration of AAA in $\mathrm{Kit}^{W-s h} / \mathrm{Kit}^{W-s h}$ mice reconstituted with IL- 6 - and IFN- $\gamma$-deficient BMMCs did not result from altered maturation of IL- 6 - or IFN- $\gamma$-deficient BMMCs. Granular morphology, tryptase production, and cell-surface expression of Fce R of IL-6- and IFN- $\gamma$-deficient BMMCs did not differ from 


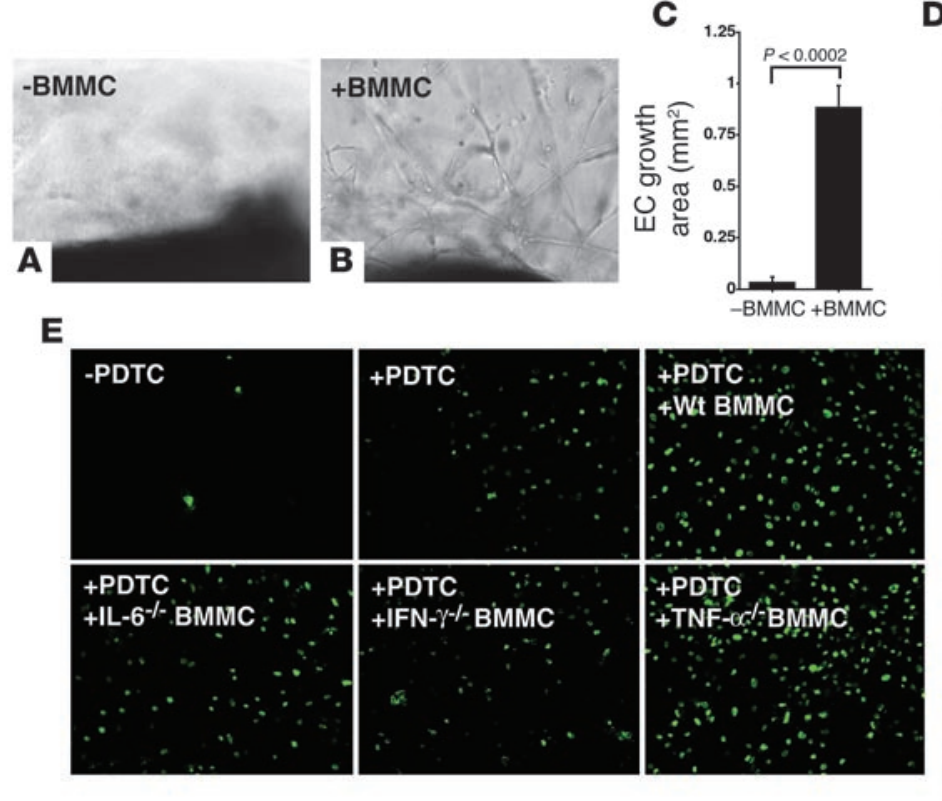

D
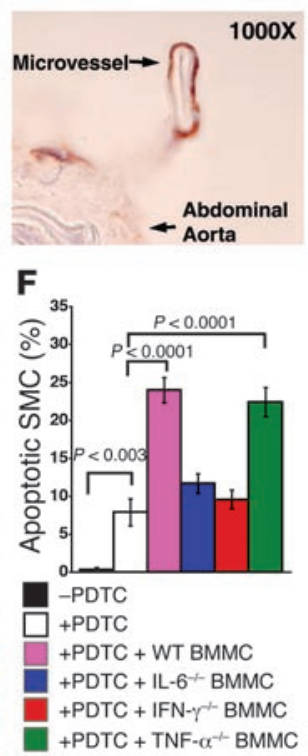

\section{Figure 6}

Mast cells promote microvessel growth and aortic SMC apoptosis. (A) RPMI media were used as a negative control for the aortic ring assay. (B) WT BMMC supernatant-induced microvessel sprouting from the aortic ring. (C) EC growth area quantification. (D) CD31 immunostaining demonstrated a microvessel surrounded by $C D 31^{+} E C s$ in an aortic ring assay. (E) PDTC-induced mouse aortic SMC apoptosis is augmented differently by BMMCs from different kinds of mice. (F) Quantification of apoptotic cell percentage. Data are presented as mean \pm SE of 4 independent experiments, and $P<0.05$ was considered significant (Mann-Whitney test). those of WT BMMCs (19). Further, immunostaining with antibodies against mouse chymase mMCP-4 demonstrated that the accumulation of IL-6- or IFN- $\gamma$-deficient mast cells that appeared in reconstituted $K i t^{W-s h} / K_{i t}^{W-s h}$ mouse abdominal aortas 14 days after perfusion $\left(19.3 \pm 7.4\right.$ and $24.5 \pm 3.7$ mast cells $/ \mathrm{mm}^{2}$, respectively) did not differ significantly from that in abdominal aortas of WT or TNF- $\alpha$-deficient BMMC-reconstituted $K i t^{W-s h} / K_{i t}^{W-s h}$ mice (29.7 \pm 6.8 and $20.2 \pm 4.9$ mast cells $/ \mathrm{mm}^{2}$, respectively), indicating similar recruitment of the IL- 6 - and IFN- $\gamma$-deficient mast cells to the abdominal aortas following elastase perfusion. Therefore, mast cell-derived IL- 6 and IFN- $\gamma$ may play key roles in aortic remodeling and expansion. In agreement with this hypothesis, aortas from $K i t^{W-s h} / K i t^{W-s h}$ mice and those reconstituted with IFN- $\gamma$ - and IL-6deficient BMMCs had significantly fewer IFN- $\gamma$-positive areas than those in aortic lesions from $\mathrm{Kit}^{W-s h} / \mathrm{Kit}^{W-s h}$ mice reconstituted with WT or TNF- $\alpha$-deficient BMMCs (Figure 4, C and D). The AAA tissue extract ELISA detected significant reduction of IL-6 in $K i t^{W-s h} / K i t^{W-s h}$ mice relative to WT mice (Figure 4E). Therefore, from these experiments, we conclude that mast cell-derived IL- 6 and IFN- $\gamma$ play key roles in aortic remodeling and expansion.

Control of $A A A$ by regulating mast cell activation. Activation of mast cells and the subsequent release of their granular constituents is a major mechanism whereby mast cells participate in pathobiological processes (24). Mast cells likely affect AAA pathogenesis by releasing IL-6, IFN- $\gamma$ (Figure 4, A-E), and possibly other unmeasured molecules. Therefore, blocking IL- 6 and IFN- $\gamma$ release might control AAA formation, a hypothesis tested in atherosclerotic apoEdeficient mice (13). To determine whether regulation of mast cell activation controls AAA formation, we injected compound 48/80 (C48/80, $4 \mathrm{mg} / \mathrm{kg} / \mathrm{d})$, a mast cell degranulation agent, or DSCG $(25 \mathrm{mg} / \mathrm{kg} / \mathrm{d})$, a mast cell stabilizer, i.p. during AAA formation. In WT mice, mast cell activation induced by C48/80 increased aortic expansion by $40 \%$ (Figure 4F). In contrast, the mast cell stabilizer DSCG reduced aortic expansion by $40 \%$, suggesting that reduced mast cell degranulation limits AAA development. Further, increased AAA in C48/80-treated mice and decreased AAA in DSCG-treated mice corresponded with changes in IEL fragmentation (Figure 4G), suggesting that mast cells regulate the activities of aortic elastases. Importantly, increased lesion sizes in C48/80-treated mice accompanied enhanced lesion macrophage contents (Figure 4B) but did not alter lesion mast cell accumulation as detected by mMCP-4 immunostaining (Figure $4 \mathrm{H}$ ), suggesting that $\mathrm{C} 48 / 80$ promotes mast cell activation or degranulation and thereby augments the release of mast cell mediators. Immunohistological analysis and ELISA of AAA tissue extracts from C48/80-treated mice revealed significantly higher levels of both IFN- $\gamma$ (Figure 4, C and D) and IL-6 (Figure 4E), which could be the result of mast cell activation/degranulation by $\mathrm{C} 48 / 80$. In contrast, impaired AAA lesions in DSCGtreated mice also showed reduced mast cell numbers (Figure $4 \mathrm{H}$ ), macrophage contents (Figure 4B), and lesional IFN- $\gamma$ (Figure 4, $\mathrm{C}$ and D) and IL-6 (Figure 4E) levels, suggesting DSCG affects AAA beyond mast cell stabilization, possibly via an antiinflammatory effect (25). Alternatively, altered lesion macrophage contents and IFN- $\gamma$ and IL- 6 levels could also be secondary to corresponding changes of AAA lesion formation in C48/80- or DSCG-treated mice. Nevertheless, our data demonstrate an impact of C48/80 and DSCG in AAA growth and reveal a potential novel target for AAA prevention and management in humans.

Expression of elastinolytic cathepsins and MMPs in mouse AAA. Elastases play essential roles in arterial wall remodeling, including atherosclerosis and AAA. Deficiencies in elastinolytic cathepsins $\mathrm{S}(26), \mathrm{K}(27)$, and L (16) reduce atherogenesis in mice. Mice deficient in cathepsins C (28) or S (unpublished data) and MMP-9 or MMP-2 $(4,5)$ also develop significantly less AAA in experimental models. Mast cells release a unique set of proteases, i.e., tryptase and chymase, that may participate in AAA directly or indirectly by activating MMP (11). Our recent in vitro study demonstrates that mast cells induce elastinolytic cathepsin expression in both aortic SMCs and ECs (19). Labeling the cysteine protease active site with [ $\left.{ }^{125} \mathrm{I}\right] \mathrm{JPM}$ (29) (Figure 5, A and B) and determining MMP activity by gelatin zymography (Figure 5, A and C) (30) revealed much lower cathepsin and MMP activities in aortic extracts from $K i t^{W-s h} / K t^{W-s h}$ mice than in WT mice 14 days after elastase perfusion. Importantly, the activities of cathepsin and MMP in 
the aortas of $K i t^{W-s h} / \mathrm{Kit}^{W-s h}$ mice increased following reconstitution with BMMCs from WT or TNF- $\alpha$-deficient mice but not those from IL-6- or IFN- $\gamma$-deficient mice (Figure 5, B and C), suggesting that mast cell-derived IL- 6 and IFN- $\gamma$ stimulate matrix-degrading protease IEL degradation (Figure 4, F and G). These observations agree with prior in vitro studies (19). BMMCs from IL-6- or IFN- $\gamma$ deficient mice produce less than 5\% IL- 6 or IFN- $\gamma$ of those from WT mice. In contrast, BMMCs from TNF- $\alpha$-deficient mice release $50 \%$ IL- 6 and $30 \%$ IFN- $\gamma$ of those from WT mice and thus may suffice to induce vascular cell protease expression in vitro (19) and in vivo (Figure 5, B and C). Activities of both cathepsin (e.g., cathepsin B) and MMP (e.g., MMP-2) increased in aortic extracts from C48/80treated mice but decreased to the levels found in $\mathrm{Kit}^{\mathrm{W}-\mathrm{sh}} / \mathrm{Kit}^{\mathrm{W}-\mathrm{s} h}$ mice following the stabilization of mast cells with DSCG (Figure 5, A-C) when both assays contained an equal amount of proteins (Figure 5A). In situ elastin zymography optimized for cysteine proteases ( $\mathrm{pH} 5.5$ with both EDTA and dithiothreitol) supported these observations. While negligible elastinolytic activities (green fluorescence in the adventitia) were detected in normal aorta, saline-treated aorta, and heat-inactivated elastase-treated aorta, AAA lesions in WT mice showed much higher elastinolytic activity than did those from $K i t^{W-s h} / K i t^{W-s h}$ mice, as indicated by the differences in percentage area of adventitia fluorescence in Figure 5D. Media green fluorescence may come from both increased elastase activity in AAA lesions and intact elastin filament autofluorescence, which also appeared in normal aorta and in experiments in which elastin substrate was not utilized (Figure 5D). The nonselective cathepsin inhibitor E64d $(20 \mu \mathrm{M})$ greatly inhibited such activity in parallel sections. Increased AAA expansion (Figure 4F) and IEL fragmentation (Figure 4G) in mice treated with the mast cell activator C48/80 accompanied enhanced in situ activity of cathepsin elastase. Likewise, impaired AAA and reduced IEL degradation in DSCG-treated mice (Figure 4, F and G) may have resulted, at least in part, from a reduction in elastinolytic cathepsin activity (Figure 5D). Omission of fluorogenic elastin substrate was utilized for the control (Figure 5D).

Role of mast cells in neovascularization and aortic SMC apoptosis. Angiogenesis and apoptosis, like elastinolysis, are common in human AAA (20). Inhibition of angiogenesis or apoptosis reduces AAA formation in rodents $(31,32)$. In $\mathrm{Kit}^{\mathrm{W}-\mathrm{s} h} / \mathrm{Kit}^{\mathrm{W}-\mathrm{sh}}$ mice, decreases in the number of microvessels (Figure $2 \mathrm{~K}$ ) and total apoptotic cells (Figure 2F) suggest that mast cells participate in these pathologic events. After incubating mouse aortic rings in Matrigel with degranulated mast cell supernatant from WT mice (Figure 6, $B$ and $C$ ) but not after incubation with culture medium alone (Figure 6, A and C), microvessel sprouting, similar to that seen in the aortic rings treated with IL- $6-$, IFN- $\gamma$-, and TNF- $\alpha$-deficient mast cell supernatant (data not shown), occurred at substantial levels, suggesting that additional factors from mast cells contributed to microvessel growth in AAA. Immunostaining a cross section of the Matrigel with mouse CD31 antibody revealed wellformed microvessels derived from the aorta after stimulation with medium conditioned by mast cell degranulation (Figure 6D).

$\alpha$-Actin staining of SMCs of AAA lesions in WT mice showed areas negative for $\alpha$-actin (Figure $2 \mathrm{G}$ ) but rich in apoptotic cells (Figure $2 \mathrm{H}$ ) in contrast to reduced apoptotic cells in lesions of $K i t^{W-s h} / K i t^{W-s h}$ mice (Figure $2 \mathrm{~F}$ ), consistent with a role of mast cells in aortic SMC apoptosis (33). To identify mast cell-derived mediators important for SMC apoptosis, we used pyrrolidine dithiocarbamate (PDTC) with or without supernatant from degranulated
BMMCs to induce apoptosis of mouse aortic SMCs. TUNELpositive cells appeared within hours. However, supernatant from degranulated BMMCs from WT and TNF- $\alpha$-deficient mice but not that from IL-6- and IFN- $\gamma$-deficient mice enhanced SMC apoptosis (Figure 6, E and F), supporting a role of mast cell-derived IL-6 and IFN- $\gamma$ in aortic SMC apoptosis.

\section{Discussion}

Although mast cells have been identified in human AAA lesions, evidence for a direct participation of mast cells in this vascular disease is lacking. The availability of mast cell-deficient mice and established mouse AAA models made it possible to determine whether these cells are essential mediators of AAA and not merely a hallmark.

This study used a BMMC reconstitution technique to determine whether mast cell-derived IL-6, IFN- $\gamma$, and TNF- $\alpha$ play a role in AAA formation (Figure 4A). TNF- $\alpha$ is expressed in macrophages and lymphocytes both in the atherosclerotic (34) and AAA (35) lesions. In ApoE $/-$ mice with diet-induced atherosclerosis, a lack of TNF- $\alpha$ reduces atherosclerosis (36). In this model, TNF- $\alpha$ plays a proatherogenic role by upregulating expression of the vascular adhesion molecules ICAM-1 and VCAM-1 and the chemokine MCP-1 in the vascular wall and by inducing expression of scavenger receptor class A and uptake of oxidized LDLs in macrophages. Although it remains to be determined whether TNF- $\alpha$ plays a similar role to that in atherosclerosis, both serum (37) and aneurysmal tissues (35) from AAA patients have increased TNF- $\alpha$ levels. However, our data with TNF- $\alpha^{-/-}$mast cells did not support a direct role of mast cell-derived TNF- $\alpha$ in AAA. This does not exclude the possibility that TNF- $\alpha$ plays a role in AAA formation; rather, it is possible that TNF- $\alpha$ produced from other cells may compensate for its absence from mast cells.

AAA formation requires mast cell IFN- $\gamma$ and IL- 6 but not TNF- $\alpha$. Reconstitution of mast cell-deficient $K i t^{W-s h} / K_{i t}{ }^{W-s h}$ mice with IFN- $\gamma^{-/-}$or IL-6 $6^{-/}$BMMCs did not restore the AAA phenotype (Figure 4A). These observations agree with the findings in IFN- $\gamma^{-/}$ mice (3), which are protected from $\mathrm{CaCl}_{2}$-induced AAA. Both this study (3) and others using a histocompatibility-mismatched aortic transplantation model in IFN- $\gamma$ receptor-deficient recipient mice (6) demonstrated that Th2-slanted immune responses promote AAA formation. Indeed, mast cells from IL-6 $6^{-/-}$and IFN- $\gamma^{-/-}$mice produce negligible IFN- $\gamma$ and IL-6, suggesting cooperative regulation of these 2 cytokines (19). HeLa cells and monocytes exhibit IFN- $\gamma$-regulated expression of IL- $6(38,39)$. Enhanced IL-6 and IFN- $\gamma$, which may come in part from mast cells, were detected in cultured explants of human AAA lesions and in serum of AAA patients $(15,40)$. AAA sections or tissue extracts from WT mice contained much higher levels of both IFN- $\gamma$ and IL- 6 than those from $\mathrm{Kit}^{W-s h} / \mathrm{Kit}^{W-s h}$ mice (Figure 4, C-E). In addition to their possible roles in activating macrophages and inducing MMP and cysteine protease expression (41), which are also critical to AAA formation $(4,5)$, IL- 6 and IFN- $\gamma$ appeared to regulate the formation of AAA by modulating lesional SMC apoptosis (Figure 6, E and F). Our observations from in vitro cell-based assay and the murine AAA model not only demonstrate that mast cell-derived IL- 6 and IFN- $\gamma$ are essential to AAA but also suggest that other sources of IL- 6 and IFN- $\gamma$, e.g., inflammatory cells such as T cells (3) and macrophages (42), do not compensate for their absence in mast cells. Such cell type-dependent functional specificity is not unique to IL-6 and IFN- $\gamma$, as similar activity has been reported for other cytokines. For example, mast cell TNF- $\alpha$ is required for recruiting neutrophils to 
infected tissue compartments (43), macrophage and neutrophil TNF- $\alpha$ are required for resistance to intracellular Listeria infection, and $\mathrm{T}$ cell TNF- $\alpha$ is required for protection from high bacterial loads (44). Thus, while it may seem intuitive that, because cytokines are made by many cell types, the absence of their production by one cell type would be compensated for by their production by another cell type, when tested in experimental models, this compensation does not always prove to be true, and depending on the end point measured, a single cellular source of a cytokine can have profound influence over modulating that end point.

Our in vitro experiments demonstrate that mast cell-derived IL- 6 and IFN- $\gamma$ are required for apoptosis but not neovascularization. Insignificant differences in the microvessel growth from the aortic ring Matrigel assay between WT and IL-6-, IFN- $\gamma-$, and TNF- $\alpha$-deficient BMMCs suggest that mast cell mediators other than IL-6, IFN- $\gamma$, and TNF- $\alpha$ modulate neovascularization in this assay even though IFN- $\gamma$, IL- 6 , and TNF- $\alpha$ have been implicated in angiogenesis. In fact, mast cell-derived bFGF, angiopoietin-1, chymase/tryptase, and a number of other proinflammatory cytokines and chemokines (45) have been implicated in angiogenesis. These mast cell mediators may have obscured the effect of mast cell IL-6, IFN- $\gamma$, and TNF- $\alpha$ in our in vitro assays (Figure 6, A-C).

Pharmacologic regulation of mast cell activation and degranulation directly controlled AAA formation in mice (Figure 4, F and G). These data not only strengthen the hypothesis that mast cells are essential mediators of AAA pathogenesis but also suggest that treatments blocking mast cell degranulation may prevent or delay AAA progression in humans. Compound $48 / 80$ has been widely used to degranulate mast cells in live animals (46). Although the detailed mechanisms of how C48/80 activates mast cells need to be investigated further, recent observations suggest that C48/80 acts on mast cells via activation of phospholipase $D(47)$ and $G_{\alpha i 3}$ $G$ protein subunits (48) to trigger the release of histamine as well as other granule components including cathepsins and MMP-activating chymases or cytokines, which may influence neighboring vascular cells. This hypothesis is supported by the findings of increased cysteine protease and MMP activities, elevation of AAA tissue IFN- $\gamma$ and IL-6, and enhanced medial elastin degradation in aortic tissues isolated from C48/80-treated mice (Figure 4). In contrast, DSCG is a drug widely used in the treatment of asthmatic patients. Observations from in vitro tests and animal models show that the effect of DSCG is related to mast cell stabilization. Importantly, this compound reduces mouse AAA by $40 \%$ (Figure 4). Impaired AAA in DSCG-treated mice is likely due to reduced release of mast cell granule contents. This hypothesis is consistent with reduced AAA lesion cysteine protease and MMP activities and IFN- $\gamma$ and IL-6 levels found in DSCG-treated mice (Figures 4 and 5).

While this study provides evidence that mast cells regulate AAA formation, it also leaves several important questions unanswered. First, depletion of neutrophils in mice impairs elastase perfusioninduced AAA (2), and mice lacking T lymphocytes have protection from $\mathrm{CaCl}_{2}$-induced AAA (3). Determination of whether lack of mast cells in the current study affected the function of either neutrophils or $\mathrm{T}$ lymphocytes will require further investigation. Although we did not find significant differences of elastase activity of neutrophils from WT and $\mathrm{Kit}^{\mathrm{W}-\mathrm{sh}} / \mathrm{Kit}^{\mathrm{W} \text {-sh }}$ mice, unrecognized interactions between these cell types may exist. Second, it remains unknown what mediated the increased number of mast cells in the injured aortas following elastase perfusion. Five weeks after reconstitution, we detected few if any mast cells in the aortas. In contrast, elastase perfusion enhanced mast cell numbers in the aortas. One possible explanation is that elastase perfusion induces aortic wall SMC expression of chemokines MCP-1 and RANTES (49), which may attract mast cells (50). Further, elastase perfusion may generate elastin degradation products that signal fibroblast, monocyte, and macrophage chemotaxis (51). Delineation of the exact mechanism will require further investigation. Third, mast cell-mediated neovascularization and SMC apoptosis remain poorly understood. Although our data suggest that SMC apoptosis involves mast cell-derived IFN- $\gamma$ and IL-6, whether these cytokines regulate SMC apoptosis directly or indirectly remains unknown. Our prior study demonstrated that mast cell IFN- $\gamma$ and IL- 6 augment SMC and EC expression of cysteine proteases (19), which participate in cell apoptosis (52). IFN- $\gamma$ and IL-6 from mast cells may have induced cathepsin expression and further led to SMC apoptosis, a hypothesis that has not been tested in the current study. Fourth, it remains uncertain whether increased expression and activities of cathepsins and MMP in AAA lesions (Figure 5) come from mast cells or other vascular cells. Mast cells contain large quantities of cathepsins (53) and mast cell chymases that participate importantly in MMP activation (11). However, mast cell cytokines (e.g., IL-6 and IFN- $\gamma$ ) are known stimulators of cathepsin and MMP expression, and our previous study (19) and the current study demonstrate concurrently their importance in arterial wall remodeling. Therefore, it is possible that mast cells contribute to AAA by releasing both proteases and cytokines, a hypothesis that requires further investigation.

In summary, data from this study establish that mast cells play a role in the development of AAA by affecting matrix-degrading protease expression, medial SMC apoptosis, and microvessel growth. More importantly, our data suggest a novel and effective therapeutic strategy to control human AAA progression by preventing release of mast cell products using mast cell-stabilizing compounds.

\section{Methods}

AAA production. Eight- to ten-week-old male WT mice (from The Jackson Laboratory, C57BL/6 background) and male $\mathrm{Kit}^{W-s h} / \mathrm{Kit}^{\mathrm{W}-\mathrm{sh}}$ mice $(\mathrm{C} 57 \mathrm{BL} / 6$ background) $(17,21)$ were used for aortic elastase perfusion, as detailed elsewhere (4). Aortic diameters were measured before the surgery (day -1 ), immediately following elastase perfusion (day 0), and 7, 14, and 56 days after perfusion. Abdominal aortas were harvested at each time point. Lumen diameters were determined by measuring the lumen perimeters of cross sections of frozen aortas.

To produce AAA by periaortic chemical injury, 8-week-old male mice were used for aorta $\mathrm{CaCl}_{2}$ injury as described (5). Aortic diameters were measured before $\mathrm{CaCl}_{2}$ application and 6 weeks after the injury.

To harvest AAA tissues, after measuring the aortic diameter and collecting the blood, we removed the aortic zone of maximal expansion, either directly freezing the tissue for protein extraction or OCT embedding for cross section preparation. Immunohistological analysis used $6-\mu \mathrm{m} \mathrm{sec}-$ tions while in situ elastin zymography used $8-\mu \mathrm{m}$ cross sections. All mouse experiments were performed under a protocol preapproved by the Animal Research Committee of Harvard Medical School.

BMMC preparation and reconstitution. WT $(\mathrm{C} 57 \mathrm{BL} / 6), \mathrm{IFN}-\gamma^{-/-}$(congenic C57BL/6, N10), IL-6-/- (congenic C57BL/6, N11), and TNF- $\alpha^{-/-}$ (C57BL/6*129/Sv, N1) mice were obtained from The Jackson Laboratory. TNF- $\alpha^{-/-}$mice were backcrossed to a congenic C57BL/6 background (N10). Bone marrow was isolated from these mice for BMMC differentiation for 5 weeks in the presence of recombinant murine IL-3 (PeproTech) and murine stem cell factor (PeproTech) as reported (21). At this time, the cell popula- 
tions consisted of more than $95 \%$ mast cells as assessed by the presence of metachromatic granules in toluidine blue-stained cells and FACS analysis for the disappearance of progenitor cell marker stem cell antigen-1. To reconstitute BMMCs in vivo, the tail veins of 5-week-old male $\mathrm{Kit}^{\mathrm{W}-\mathrm{sh}} / \mathrm{Kit}^{\mathbb{W}-\mathrm{sh}}$ mice were injected with BMMCs $\left(1 \times 10^{7}\right.$ cells/mouse). Mice were perfused with elastase to produce AAA 5 weeks after reconstitution.

Mast cell activation and stabilization in vivo. C48/80 activated the mast cells in WT mice, and DSCG stabilized the mast cells in WT mice. After mice (C57BL/6, male, 10 weeks old) recovered from elastase perfusion surgery (day 0), they received the first i.p. injection of C48/80 (Sigma-Aldrich, $4 \mathrm{mg} / \mathrm{kg} / \mathrm{d}$ ) or DSCG (Sigma-Aldrich, $25 \mathrm{mg} / \mathrm{kg} / \mathrm{d}$ ). Each animal received daily injection for the duration of the experiment thereafter (14 days).

Mast cell content measurement. Immunostaining with rabbit anti-mouse mMCP-4 antibody (1:150) determined the mast cell number on aortic sections (19). Antibody specificity was confirmed using WT mouse AAA sections immunostained with rabbit preimmune serum and $\mathrm{Kit}^{W-s b} / \mathrm{Kit}^{W-s}$ mouse aortic sections immunostained with the mMCP-4 antibody at the same antibody dilution. The total number of mMCP-4-positive cells on each section were counted manually and blindly, and the total area was determined using computer-assisted image analysis (Image-Pro Plus; MediaCybernetics).

Immunohistochemistry, ELISA, and lesion characterization. Frozen sections $(6 \mu \mathrm{m})$ were stained for macrophages (Mac-3), T cells (CD3), SMCs ( $\alpha$-actin), ECs (CD31), mast cells (mMCP-4), elastin (Verhoeff-van Gieson), and IFN- $\gamma$ as described previously $(19,26)$. Lesion apoptotic cells were determined with the In situ Apoptosis Detection kit according to the manufacturer's instructions (Chemicon International). Elastin degradation and lesion SMC content were graded according to the grading keys shown in Figure 2, $\mathrm{C}$ and $\mathrm{D}$. To determine lesion IL-6 levels, frozen aortas were pulverized for protein extraction in a $\mathrm{pH} 7.5$ buffer containing $50 \mathrm{mM} \mathrm{NaAc}$ and $1 \%$ Triton X-100. Protein concentration was determined with a BCA kit (Bio-Rad) and IL- 6 levels measured by ELISA (R\&D Systems). All immunostained cells were counted or calculated blindly by at least 2 observers.

Cysteine protease active site labeling and gelatin gel in situ zymogram. Pulverized aortic tissues were lysed in a $\mathrm{pH} 5.5$ buffer. The cysteine protease activity in tissue lysates was determined with [125I]JPM labeling ( $2 \mu \mathrm{g}$ protein/lane) (29), and the MMP activity was assessed by in-gel gelatinase zymogram assay (5 $\mu \mathrm{g}$ protein/lane) as described (30). Equal protein loading ( $7 \mu \mathrm{g}$ protein/ lane) was confirmed by SDS-PAGE followed with Coomassie staining.

Mast cell degranulation, aortic ring assay, and SMC apoptosis assay. In vitro-differentiated BMMCs were degranulated with mouse anti-DNP IgE monoclonal antibody as described previously (54). Degranulation efficiency was calculated as follows: (experimental supernatant - control supernatant)/ (experimental supernatant + experimental cell lysates supernatant).

An aortic ring assay was used to test mast cell function in angiogenesis. In brief, a 96-well plate was coated with $50 \mu \mathrm{l}$ of Matrigel (BD Biosciences). A 1-mm-long mouse aortic ring was laid on the top of the Matrigel and covered with $100 \mu \mathrm{l}$ of Matrigel. After solidification, $100 \mu \mathrm{l}$ of RPMI (10\% FBS) with or without $100 \mu \mathrm{l}$ of degranulated BMMC supernatant was added to each well. After 7-10 days of culture, the aortas were photographed and the endothelial outgrowth was analyzed using Image-Pro Plus software. To confirm a microvessel phenotype of sprouts from the aortic ring, a Matrigel containing aortic ring and sprouts was embedded in OCT followed by sectioning and immunostaining with CD31.
Mouse aortic SMC apoptosis was induced with $50 \mu \mathrm{M}$ of PDTC (SigmaAldrich) as previously described with or without degranulated mast cell supernatant prepared from the same amount of BMMCs (55). Apoptotic SMCs were detected using the in situ cell death detection kit according to the manufacturer's instructions (Roche Applied Science). Data were presented as mean \pm SE of percentage of apoptotic cells.

In situ elastin zymography. AAA lesion elastinolytic activity was determined in 8- $\mu \mathrm{M}$ frozen sections using elastin conjugated with quenched fluorescein (DQ elastin; Invitrogen) as a substrate, which requires cleavage by elastinolytic enzymes to become fluorescent. In brief, DQ elastin $\left(1 \mathrm{mg} / \mathrm{ml}\right.$ in $\left.\mathrm{H}_{2} \mathrm{O}\right)$ was mixed 1:10 with $1 \%$ low-melting agarose (Sigma-Aldrich). This mixture $(20 \mu \mathrm{l})$ was added on top of each section, coverslipped, and gelled at $4^{\circ} \mathrm{C}$. Following incubation at $37^{\circ} \mathrm{C}$ ( 48 hours), fluorescence was examined under fluorescent microscopy. Cysteine protease activity was determined using an EDTA-containing pH 5.5 buffer (56) with or without E64d (20 $\mu \mathrm{M})$. Zymographic images were acquired using identical shutter conditions. The percentage of fluorescence intensity of each cross section, excluding the media area due to medial elastin filament autofluorescence, was measured using computer-assisted image quantification (Image-Pro Plus software).

Neutrophil and monocyte elastase activity assay. Neutrophils from WT and $K i t^{W-s h} / K_{i t}^{W-s h}$ mice were prepared from bone marrow by gradient centrifugation. Bone marrow cells were overlaid on the top of $62.5 \%$ Percoll (Sigma-Aldrich) followed by centrifugation at $600 \mathrm{~g}$ for 30 minutes. Purified neutrophils were lysed in a pH 8.5 buffer containing $150 \mathrm{mM}$ $\mathrm{NaCl}, 200 \mathrm{mM}$ Tris $\mathrm{HCl}$, and $1 \%$ Triton X-100. Monocytes from WT and $\mathrm{Kit}^{W-s b} / \mathrm{Kit}^{W-s h}$ mice were isolated from blood by overlaying diluted blood (1:1 in PBS) on LSM Lymphocyte Monocyte Separation Medium (LLC; $\mathrm{MP}$ ). Isolated monocytes were lysed in a $\mathrm{pH} 5.5$ buffer containing $50 \mathrm{mM}$ $\mathrm{NaAc}, 1 \%$ Triton X-100, and $12 \mathrm{mM}$ dithiothreitol. Equal amounts of protein $(60 \mu \mathrm{g})$ were added to a final volume of $100 \mu \mathrm{l}$ with $50 \mu \mathrm{g}$ of elastin conjugated with quenched fluorescein (DQ elastin; Invitrogen) followed by incubation at $37^{\circ} \mathrm{C}$ for 24 hours. Elastase activity was determined by measuring the $\mathrm{OD}_{513 \mathrm{~nm}}$.

Statistics. The statistical significance of data sets from this study was examined with a nonparametric Mann-Whitney test. Data from the gel densitometry analysis were also analyzed using the nonparametric Mann-Whitney test due to the relatively small sample sizes and the nonGaussian distribution of the data. $P$ values of less than 0.05 were considered significant.

\section{Acknowledgments}

The authors thank Eugenia Shvartz for technical and Joan Perry for editorial assistance. This work is supported by NIH grants HL60942 and HL67283 (to G.-P. Shi), HL56985 (to P. Libby), HL67249 (to G.K. Sukhova), and HL75026 (to P.J. Wolters).

Received for publication December 21, 2006, and accepted in revised form July 26, 2007.

Address correspondence to: Guo-Ping Shi, Cardiovascular Medicine, NRB-7, 77 Avenue Louis Pasteur, Boston, Massachusetts 02115, USA. Phone: (617) 525-4358; Fax: (617) 525-4380; E-mail: gshi@rics.bwh.harvard.edu.
1. Ailawadi, G., Eliason, J.L., and Upchurch, G.R., Jr. 2003. Current concepts in the pathogenesis of abdominal aortic aneurysm. J. Vasc. Surg. 38:584-588.

2. Eliason, J.L., et al. 2005. Neutrophil depletion inhibits experimental abdominal aortic aneurysm formation. Circulation. 112:232-240.

3. Xiong, W., Zhao, Y., Prall, A., Greiner, T.C., and Baxter, B.T. 2004. Key roles of CD4+ T cells and
IFN-gamma in the development of abdominal aortic aneurysms in a murine model. J. Immunol. 172:2607-2612.

4. Pyo, R., et al. 2000. Targeted gene disruption of matrix metalloproteinase-9 (gelatinase B) suppresses development of experimental abdominal aortic aneurysms. J. Clin. Invest. 105:1641-1649.

5. Longo, G.M., et al. 2002. Matrix metalloproteinases
2 and 9 work in concert to produce aortic aneurysms. J. Clin. Invest. 110:625-632. doi:10.1172/ JCI200215334.

6. Shimizu, K., Shichiri, M., Libby, P., Lee, R.T., and Mitchell, R.N. 2004. Th2-predominant inflammation and blockade of IFN- $\gamma$ signaling induce aneurysms in allografted aortas. J. Clin. Invest. 114:300-308. doi:10.1172/JCI200419855. 
7. Metzler, B., and Xu, Q. 1997. The role of mast cells in atherosclerosis. Int. Arch. Allergy Immunol. 114:10-14.

8. Ihara, M., et al. 1999. Increased chymase-dependent angiotensin II formation in human atherosclerotic aorta. Hypertension. 33:1399-1405.

9. Gurish, M.F., and Boyce, J.A. 2006. Mast cells: ontogeny, homing, and recruitment of a unique innate effector cell. J. Allergy Clin. Immunol. 117:1285-1291.

10. Li, M., et al. 2004. Involvement of chymase-mediated angiotensin II generation in blood pressure regulation. J. Clin. Invest. 114:112-120. doi:10.1172/ JCI200420805.

11. Tchougounova, E., et al. 2005. A key role for mast cell chymase in the activation of pro-matrix metalloprotease- 9 and pro-matrix metalloprotease-2. J. Biol. Chem. 280:9291-9296.

12. Tsunemi, K., et al. 2004. A specific chymase inhibitor, 2-(5-formylamino-6-oxo-2-phenyl-1,6-dihydropyrimidine-1-yl)-N-[[3,4-dioxo-1-phenyl-7-(2-pyridyloxy)]-2-heptyl]acetamide (NK3201), suppresses development of abdominal aortic aneurysm in hamsters. J. Pharmacol. Exp. Ther. 309:879-883.

13. Huang, M., Pang, X., Karalis, K., and Theoharides, T. C. 2003. Stress-induced interleukin- 6 release in mice is mast cell-dependent and more pronounced in apolipoprotein E knockout mice. Cardiovasc. Res. 59:241-249.

14. Liu, J., et al. 2004. Lysosomal cysteine proteases in atherosclerosis. Arterioscler. Thromb. Vasc. Biol. 24:1359-1366.

15. Newman, K.M., Jean-Claude, J., Li, H., Ramey, W.G., and Tilson, M.D. 1994. Cytokines that activate proteolysis are increased in abdominal aortic aneurysms. Circulation. 90:II224-II227.

16. Kitamoto, S., et al. 2007. Cathepsin L deficiency reduces diet-induced atherosclerosis in low-density lipoprotein receptor-knockout mice. Circulation. 115:2065-2075.

17. Duttlinger, R., et al. 1995. The Wsh and Ph mutations affect the c-kit expression profile: c-kit misexpression in embryogenesis impairs melanogenesis in Wsh and Ph mutant mice. Proc. Natl. Acad. Sci.U.S. A. 92:3754-3758

18. Grimbaldeston, M.A., et al. 2005. Mast cell-deficient W-sash c-kit mutant Kit W-sh/W-sh mice as a model for investigating mast cell biology in vivo. Am. J. Pathol. 167:835-848.

19. Sun, J., et al. 2007. Mast cells promote atherosclerosis by releasing pro-inflammatory cytokines. Nat. Med. 13:719-724.

20. Choke, E., et al. 2006. Abdominal aortic aneurysm rupture is associated with increased medial neovascularization and overexpression of proangiogenic cytokines. Arterioscler. Thromb. Vasc. Biol. 26:2077-2082.

21. Wolters, P.J., et al. 2005. Tissue-selective mast cell reconstitution and differential lung gene expression in mast cell-deficient Kit(W-sh)/Kit(W-sh) sash mice. Clin. Exp. Allergy. 35:82-88.

22. Tanzola, M.B., Robbie-Ryan, M., Gutekunst, C.A. and Brown, M.A. 2003. Mast cells exert effects outside the central nervous system to influence experimental allergic encephalomyelitis disease course.
J. Immunol. 171:4385-4391.

23. Nakae, S., et al. 2005. Mast cells enhance T cell activation: importance of mast cell-derived TNF. Proc. Natl. Acad. Sci. U. S. A. 102:6467-6472.

24. Woolley, D.E. 2003. The mast cell in inflammatory arthritis. N. Engl. J. Med. 348:1709-1711.

25. Shichijo, M., et al. 1998. The effects of anti-asthma drugs on mediator release from cultured human mast cells. Clin. Exp. Allergy. 28:1228-1236.

26. Sukhova, G.K., et al. 2003. Deficiency of cathepsin $S$ reduces atherosclerosis in LDL receptor-deficient mice. J. Clin. Invest. 111:897-906. doi:10.1172/ JCI200314915.

27. Lutgens, E., et al. 2006. Disruption of the cathep$\sin \mathrm{K}$ gene reduces atherosclerosis progression and induces plaque fibrosis but accelerates macrophage foam cell formation. Circulation. 113:98-107.

28. Pagano, M.B., et al. 2007. Critical role of dipeptidyl peptidase I in neutrophil recruitment during the development of experimental abdominal aortic aneurysms. Proc. Natl. Acad. Sci. U. S. A. 104:2855-2860.

29. Shi, G.P., Munger, J.S., Meara, J.P., Rich, D.H., and Chapman, H.A. 1992. Molecular cloning and expression of human alveolar macrophage cathepsin S, an elastinolytic cysteine protease. J. Biol. Chem. 267:7258-7262.

30. Fang, K.C., Raymond, W.W., Lazarus, S.C., and Caughey, G.H. 1996. Dog mastocytoma cells secrete a 92-kD gelatinase activated extracellularly by mast cell chymase. J. Clin. Invest. 97:1589-1596.

31. Miwa, K., et al. 2005. Inhibition of ets, an essential transcription factor for angiogenesis, to prevent the development of abdominal aortic aneurysm in a rat model. Gene Ther. 12:1109-1118.

32. Wang, Y.X., et al. 2005. Fasudil, a Rho-kinase inhibitor, attenuates angiotensin II-induced abdominal aortic aneurysm in apolipoprotein E-deficient mice by inhibiting apoptosis and proteolysis. Circulation. 111:2219-2226

33. Leskinen, M., Wang, Y., Leszczynski, D., Lindstedt, K.A., and Kovanen, P.T. 2001. Mast cell chymase induces apoptosis of vascular smooth muscle cells. Arterioscler. Thromb. Vasc. Biol. 21:516-522.

34. Barath, P., et al. 1990. Tumor necrosis factor gene expression in human vascular intimal smooth muscle cells detected by in situ hybridization. Am. J. Pathol. 137:503-509.

35. Hamano, K., et al. 2003. Enhanced tumor necrosis factor-alpha expression in small sized abdominal aortic aneurysms. World J. Surg. 27:476-480.

36. Ohta, H., et al. 2005. Disruption of tumor necrosis factor-alpha gene diminishes the development of atherosclerosis in ApoE-deficient mice. Atherosclerosis. 180:11-17.

37. Fiane, A.E., et al. 2003. Mechanism of complement activation and its role in the inflammatory response after thoracoabdominal aortic aneurysm repair. Circulation. 108:849-856

38. Faggioli, L., et al. 1997. Molecular mechanisms regulating induction of interleukin- 6 gene transcription by interferon-gamma. Eur. J. Immunol. 27:3022-3030

39. Biondillo, D.E., Konicek, S.A., and Iwamoto, G.K.
1994. Interferon-gamma regulation of interleukin 6 in monocytic cells. Am. J. Physiol. 267:L564-L568.

40. Jones, K.G., et al. 2001. Interleukin-6 (IL-6) and the prognosis of abdominal aortic aneurysms. Circulation. 103:2260-2265.

41. Wang, Z., et al. 2000. Interferon gamma induction of pulmonary emphysema in the adult murine lung. J. Exp. Med. 192:1587-600.

42. Leon, M.L., and Zuckerman, S.H. 2005. Gamma interferon: a central mediator in atherosclerosis. Inflamm. Res. 54:395-411.

43. Echtenacher, B., Mannel, D.N., and Hultner, L. 1996. Critical protective role of mast cells in a model of acute septic peritonitis. Nature. 381:75-77.

44. Grivennikov, S.I., et al. 2005. Distinct and nonredundant in vivo functions of TNF produced by $t$ cells and macrophages/neutrophils: protective and deleterious effects. Immunity. 22:93-104

45. Hiromatsu, Y., and Toda, S. 2003. Mast cells and angiogenesis. Microsc. Res. Tech. 60:64-69.

46. Paton, W.D. 1951. Compound 48/80: a potent histamine liberator. Br. J. Pharmacol. Chemother. 6:499-508.

47. Lappalainen, H., Laine, P., Pentikainen, M.O., Sajantila, A., and Kovanen, P.T. 2004. Mast cells in neovascularized human coronary plaques store and secrete basic fibroblast growth factor, a potent angiogenic mediator. Arterioscler. Thromb. Vasc. Biol. 24:1880-1885.

48. Aridor, M., Rajmilevich, G., Beaven, M.A., and SagiEisenberg, R. 1993. Activation of exocytosis by the heterotrimeric G protein Gi3. Science. 262:1569-1572.

49. Colonnello, J.S., et al. 2003. Transient exposure to elastase induces mouse aortic wall smooth muscle cell production of MCP-1 and RANTES during development of experimental aortic aneurysm. J. Vasc. Surg. 38:138-146.

50. Conti, P., and DiGioacchino, M. 2001. MCP-1 and RANTES are mediators of acute and chronic inflammation. Allergy Asthma Proc. 22:133-137.

51. Hunninghake, G.W., et al. 1981. Elastin fragments attract macrophage precursors to diseased sites in pulmonary emphysema. Science. 212:925-927.

52. Stoka, V., Turk, B., and Turk, V. 2005. Lysosomal cysteine proteases: structural features and their role in apoptosis. IUBMB Life. 57:347-353.

53. Henningsson, F., Wolters, P., Chapman, H.A., Caughey, G.H., and Pejler, G. 2003. Mast cell cathepsins $\mathrm{C}$ and $\mathrm{S}$ control levels of carboxypeptidase $A$ and the chymase, mouse mast cell protease 5 . Biol. Chem. 384:1527-1531.

54. Wolters, P.J., Pham, C.T., Muilenburg, D.J., Ley, T.J., and Caughey, G.H. 2001. Dipeptidyl peptidase I is essential for activation of mast cell chymases, but not tryptases, in mice. J. Biol. Chem. 276:18551-18556

55. Tsai, J.C., et al. 1996. Induction of apoptosis by pyrrolidinedithiocarbamate and $\mathrm{N}$-acetylcysteine in vascular smooth muscle cells. J. Biol. Chem. 271:3667-3670

56. Galis, Z.S., Sukhova, G.K., and Libby, P. 1995. Microscopic localization of active proteases by in situ zymography: detection of matrix metalloproteinase activity in vascular tissue. FASEB J. 9:974-980. 